\title{
Capsule and Specimen Geometries for HFIR Irradiation Testing Supporting the Transformational Challenge Reactor
}

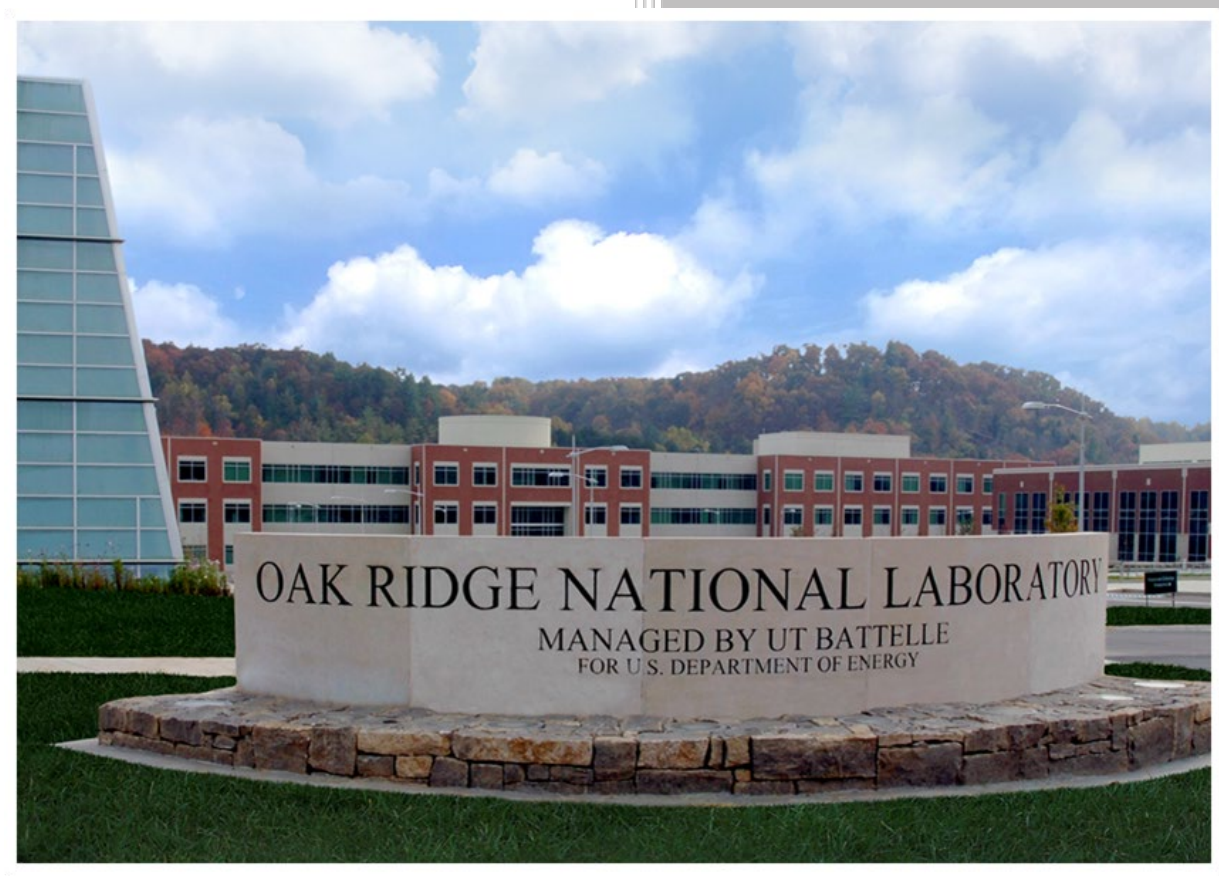

Patrick Champlin Joseph Burns Christian Petrie Xunxiang $\mathrm{Hu}$ Kory D. Linton Richard Howard Kurt A. Terrani

Approved for public release.

Distribution is unlimited.

September 10, 2019

M3CT-19OR06090120 


\title{
DOCUMENT AVAILABILITY
}

Reports produced after January 1, 1996, are generally available free via US Department of Energy (DOE) SciTech Connect.

Website www.osti.gov/

Reports produced before January 1, 1996, may be purchased by members of the public from the following source:

\author{
National Technical Information Service \\ 5285 Port Royal Road \\ Springfield, VA 22161 \\ Telephone 703-605-6000 (1-800-553-6847) \\ TDD 703-487-4639 \\ Fax 703-605-6900 \\ E-mail info@ntis.gov \\ Website http://classic.ntis.gov/
}

Reports are available to DOE employees, DOE contractors, Energy Technology Data Exchange representatives, and International Nuclear Information System representatives from the following source:

Office of Scientific and Technical Information

PO Box 62

Oak Ridge, TN 37831

Telephone 865-576-8401

Fax 865-576-5728

E-mail reports@osti.gov

Website http://www.osti.gov/contact.html

This report was prepared as an account of work sponsored by an agency of the United States Government. Neither the United States Government nor any agency thereof, nor any of their employees, makes any warranty, express or implied, or assumes any legal liability or responsibility for the accuracy, completeness, or usefulness of any information, apparatus, product, or process disclosed, or represents that its use would not infringe privately owned rights. Reference herein to any specific commercial product, process, or service by trade name, trademark, manufacturer, or otherwise, does not necessarily constitute or imply its endorsement, recommendation, or favoring by the United States Government or any agency thereof. The views and opinions of authors expressed herein do not necessarily state or reflect those of the United States Government or any agency thereof. 
Transformational Challenge Reactor

Capsule and Specimen Geometries for HFIR Irradiation Testing Supporting the Transformational Challenge Reactor

\author{
Patrick Champlin \\ Joseph Burns \\ Christian M. Petrie \\ Xunxiang $\mathrm{Hu}$ \\ Kory D. Linton \\ Richard Howard \\ Kurt A. Terrani
}

Date Published: September 10, 2019

\title{
M3CT-19OR06090120
}

Prepared by

OAK RIDGE NATIONAL LABORATORY

Oak Ridge, TN 37831-6283

managed by

UT-BATTELLE, LLC

for the

US DEPARTMENT OF ENERGY

under contract DE-AC05-00OR22725 



\section{CONTENTS}

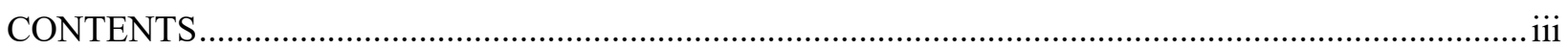

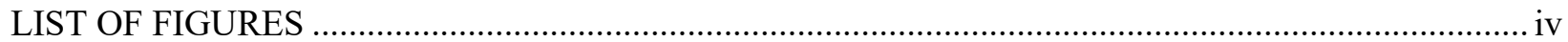

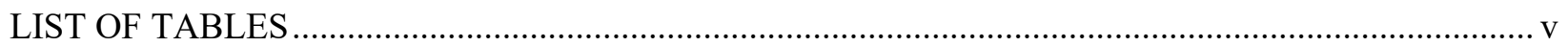

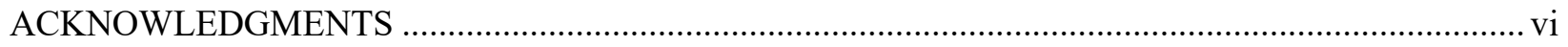

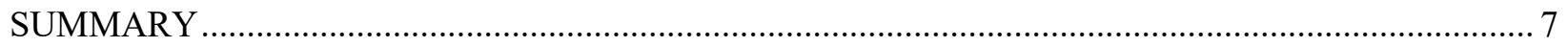

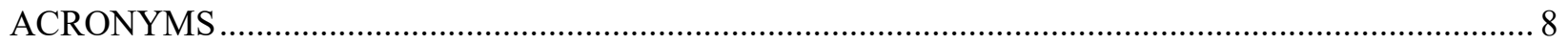

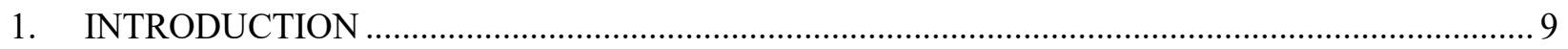

2. HIGH FLUX ISOTOPE REACTOR (HFIR) .......................................................................... 9

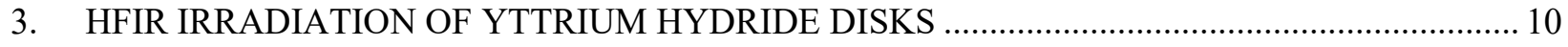

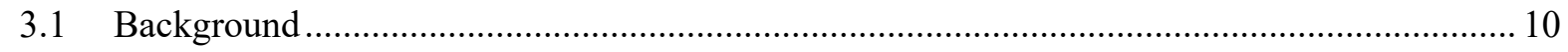

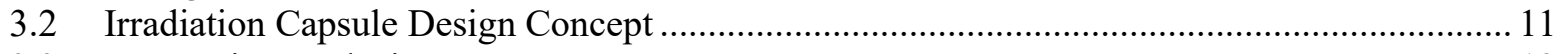

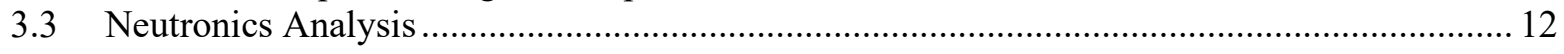

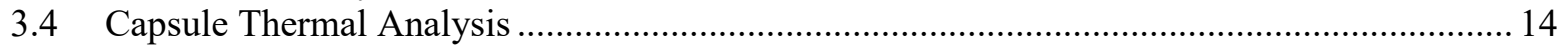

4. HFIR IRRADIATION OF 3D PRINTED SIC DISKS IRRADIATIONS .................................. 18

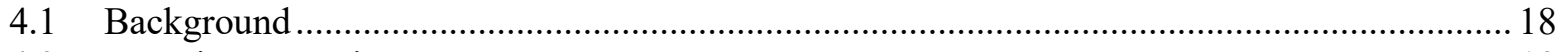

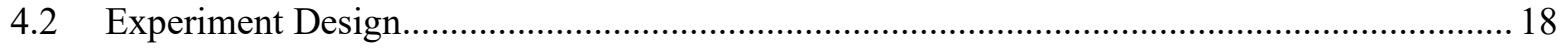

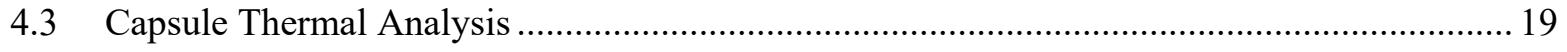

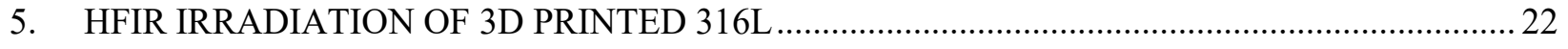

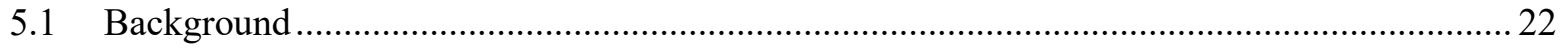

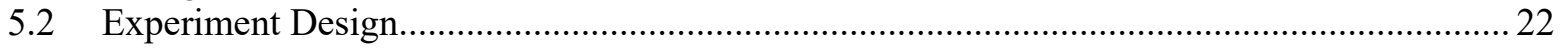

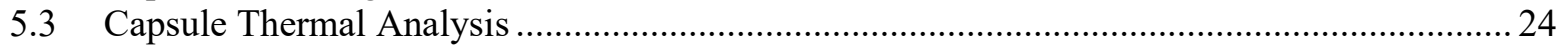

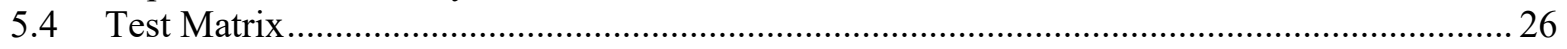

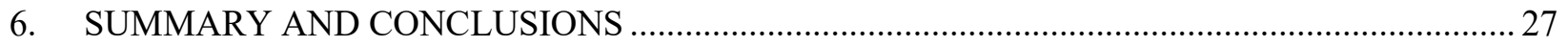

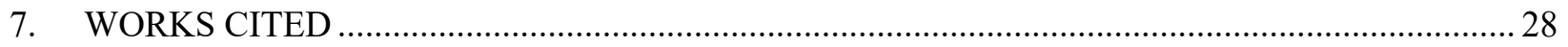




\section{LIST OF FIGURES}

Figure 1. Schematic showing transverse section view of HFIR core, reflector, and experimental positions (not to scale) [3]

Figure 2. Design of YHx irradiation capsule.

Figure 3. Temperatures in (a) the rabbit internals and (b) the specimens, for a $9.18 \mathrm{~mm}$ diameter holder and $64 \%$ helium $+36 \%$ argon fill gas for the $\mathrm{YH}_{1.7}$ irradiation capsule with a targeted temperature of $900^{\circ} \mathrm{C}$.

Figure 4. $\mathrm{YH}_{\mathrm{x}}$ specimen average temperature as a function of holder diameter and helium concentration in the housing ( $\mathrm{z}$ axis is temperature with a unit of ${ }^{\circ} \mathrm{C}$ )

Figure 5. Schematic showing the irradiation capsule design ....

Figure 6. Predicted temperature contours (in ${ }^{\circ} \mathrm{C}$ ) for the nominally $400^{\circ} \mathrm{C}$ design with $1 / 4^{-}$ symmetry showing (a) the entire capsule assembly, (b) the specimens, and (c) the passive temperature monitors

Figure 7. Predicted temperature contours (in ${ }^{\circ} \mathrm{C}$ ) for the nominally $650^{\circ} \mathrm{C}$ design with $1 / 4^{-}$ symmetry showing (a) the entire capsule assembly, (b) the specimens, and (c) the passive temperature monitors.

Figure 8. Predicted temperature contours (in ${ }^{\circ} \mathrm{C}$ ) for the nominally $900^{\circ} \mathrm{C}$ design with $1 / 4^{-}$ symmetry showing (a) the entire capsule assembly, (b) the specimens, and (c) the passive temperature monitors.

Figure 9. Section view of the GENTEN capsule design concept. .................................................... 23

Figure 10. Section view of the GENBEN capsule showing the design concept...................................... 24

Figure 11. Representative GENTEN surface response reporting average specimen temperature............. 25

Figure 12. Representative GENBEN surface response reporting average specimen temperature..............26 


\section{LIST OF TABLES}

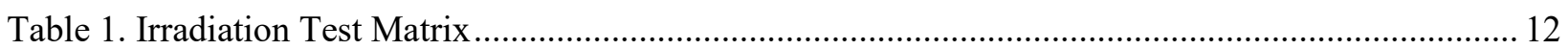

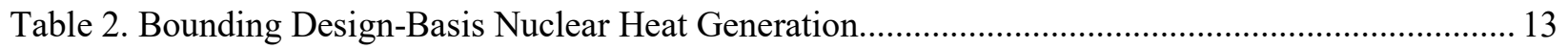

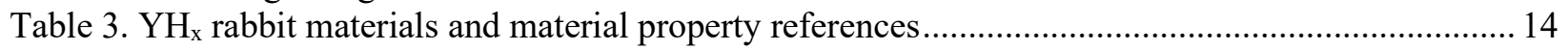

Table 4. $\mathrm{YH}_{\mathrm{x}}$ rabbit thermal boundary conditions [21] [22] [23] .................................................... 14

Table 5. Summary of component temperatures, irradiation position, holder material, fill gas, and

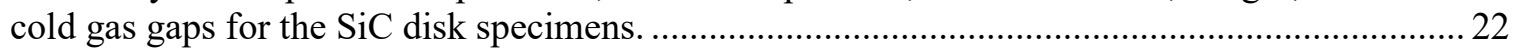

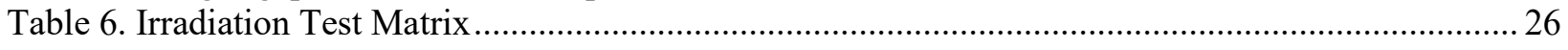

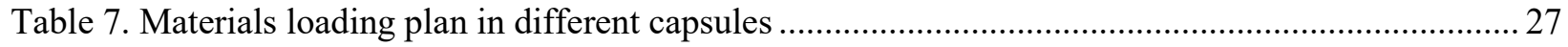




\section{ACKNOWLEDGMENTS}

This research was sponsored by the US Department of Energy (DOE), Office of Nuclear Energy. Neutron irradiation in the High Flux Isotope Reactor (HFIR) is made possible by the Office of Basic Energy Sciences, US DOE. The report was authored by UT-Battelle under Contract No. DE-AC05-00OR22725 with the DOE. 


\section{SUMMARY}

This report provides a summary of irradiation capsule design and analysis for the three main categories of materials to be used in the Transformational Challenge Reactor (TCR) core. These materials are yttrium hydride as the moderator, silicon carbide, and Grade 316L austenitic stainless steel. No neutron irradiation data exists on the former and the latter two are derived from advanced manufacturing techniques and therefor need to undergo rigorous testing to assess their behavior as function of dose and temperature. The detailed design and analysis summarized in this report is the critical step to facilitate safe and relevant irradiation of these materials to be conducted at the Oak Ridge National Laboratory (ORNL) High Flux Isotope Reactor (HFIR). These irradiations will ultimately yield critical materials properties data for reactor design and licensing purposes. 


\section{ACRONYMS}

$\begin{array}{ll}\text { BOC } & \text { beginning of cycle } \\ \text { CAD } & \text { computer-aided design } \\ \text { CVD } & \text { chemical vapor deposited } \\ \text { DAC } & \text { design and analysis calculation } \\ \text { DOE } & \text { US Department of Energy } \\ \text { EOC } & \text { end of cycle } \\ \text { FTT } & \text { flux trap target } \\ \text { GENBEN } & \text { general bend bar } \\ \text { GENTEN } & \text { general tensile } \\ \text { HFIR } & \text { High Flux Isotope Reactor } \\ \text { HT } & \text { hydraulic tube } \\ \text { LCS } & \text { limiting condition scenario } \\ \text { MCNP } & \text { Monte Carlo N-Particle } \\ \text { OD } & \text { outer diameter } \\ \text { ORNL } & \text { Oak Ridge National Laboratory } \\ \text { PTP } & \text { peripheral target position } \\ \text { SiC } & \text { silicon carbide } \\ \text { SNAP } & \text { Systems Nuclear Auxiliary Power } \\ \text { TCR } & \text { Transformational Challenge Reactor } \\ \text { TM } & \text { temperature monitor } \\ \text { TRIGA } & \text { Training, Research, Isotopes, General Atomic } \\ \text { TRRH } & \text { target rod rabbit holder } \\ \text { YH } & \text { yttrium hydride } \\ \text { ZrH } & \text { zirconium hydride }\end{array}$




\section{INTRODUCTION}

The Transformational Challenge Reactor (TCR) program intends to rapidly demonstrate application of advanced manufacturing to build and operate an advanced nuclear energy system. The TCR core will comprise novel, advanced manufactured materials, so its core materials will differ from the pre-1970s conventionally manufactured materials used to date in light water or other advanced nuclear reactor cores [1]. As a result, these materials must be thoroughly tested. This comprehensive testing campaign must include irradiation testing to provide material properties data as a function of displacement damage dose and temperature. These data are necessary to inform performance and safety analysis tools used during design and licensing of the TCR core.

The TCR core materials envisioned at this stage of the program can be divided into three main categories: (1) laser powder bed fusion derived austenitic stainless steel (Grade 316L) metal structures forming the core lattice, (2) additively manufactured (binderjet printed and chemical vapor infiltrated) silicon carbide (SiC) forming the fuel matrix, with fuel being microencapsulated (TRISO) fuel particles, and (3) the hydrogen-bearing moderator for which the TCR core is the cubic phase of yttrium hydride $\left(\mathrm{YH}_{\mathrm{x}}\right.$ with $1.5<\times<2$ ).

This report provides a brief background of neutron irradiation capabilities at the Oak Ridge National Laboratory (ORNL) High Flux Isotope Reactor (HFIR), followed by a detailed description of irradiation test capsule design and conditions for the three categories of TCR core materials.

\section{HIGH FLUX ISOTOPE REACTOR (HFIR)}

HFIR is a beryllium-reflected, pressurized, light-water-cooled and moderated flux trap-type reactor located at ORNL. HFIR's core consists of aluminum-clad involute-fuel plates which currently use highly enriched ${ }^{235} \mathrm{U}$ fuel to maintain steady state at a power level of $85 \mathrm{MW}$ [2]. Most experiments performed in HFIR are conducted in the flux trap, typically in small, uninstrumented "rabbit" capsules. As many as 7-9 rabbits can be stacked axially inside a single peripheral target position (PTP) holder, a target rod rabbit holder (TRRH), or the hydraulic tube (see Figure 1). Orifices in the TRRH and PTP holders establish the capsule heat transfer boundary conditions. Positions are numbered in increasing order from the bottom to the top of a PTP or TRRH. Positions TRRH-4 and PTP-5 are closest to the reactor's midplane.

Neutron and gamma radiation from HFIR fuel causes heating of experiment materials. This heating is accurately determined using neutronics models of the HFIR core and is used as an input to thermal analyses that predict component temperatures during irradiation. Experiments in the flux trap are almost

always uninstrumented. Either passive silicon carbide $(\mathrm{SiC})$ temperature monitors (TMs) or thermometry can be used to determine the irradiation temperature post irradiation [3]. However, detailed neutronic and thermal analyses are required to ensure that design temperatures are achieved. Experiment designs typically use a small insulating gas gap between the capsule internal components and external housing in contact with reactor coolant. The size of the gap and the choice of fill gas (typically helium, neon, or argon) inside the experiment are chosen so that the heat generated in the experimental components passes through the gas gap and gives the desired temperature drop across the gap. The temperature drop is a function of the heat flux through the gap, the thermal conductivity of the fill gas, and the size of the gas gap. Each of these parameters is carefully selected and modeled to achieve design temperature in an experiment. 


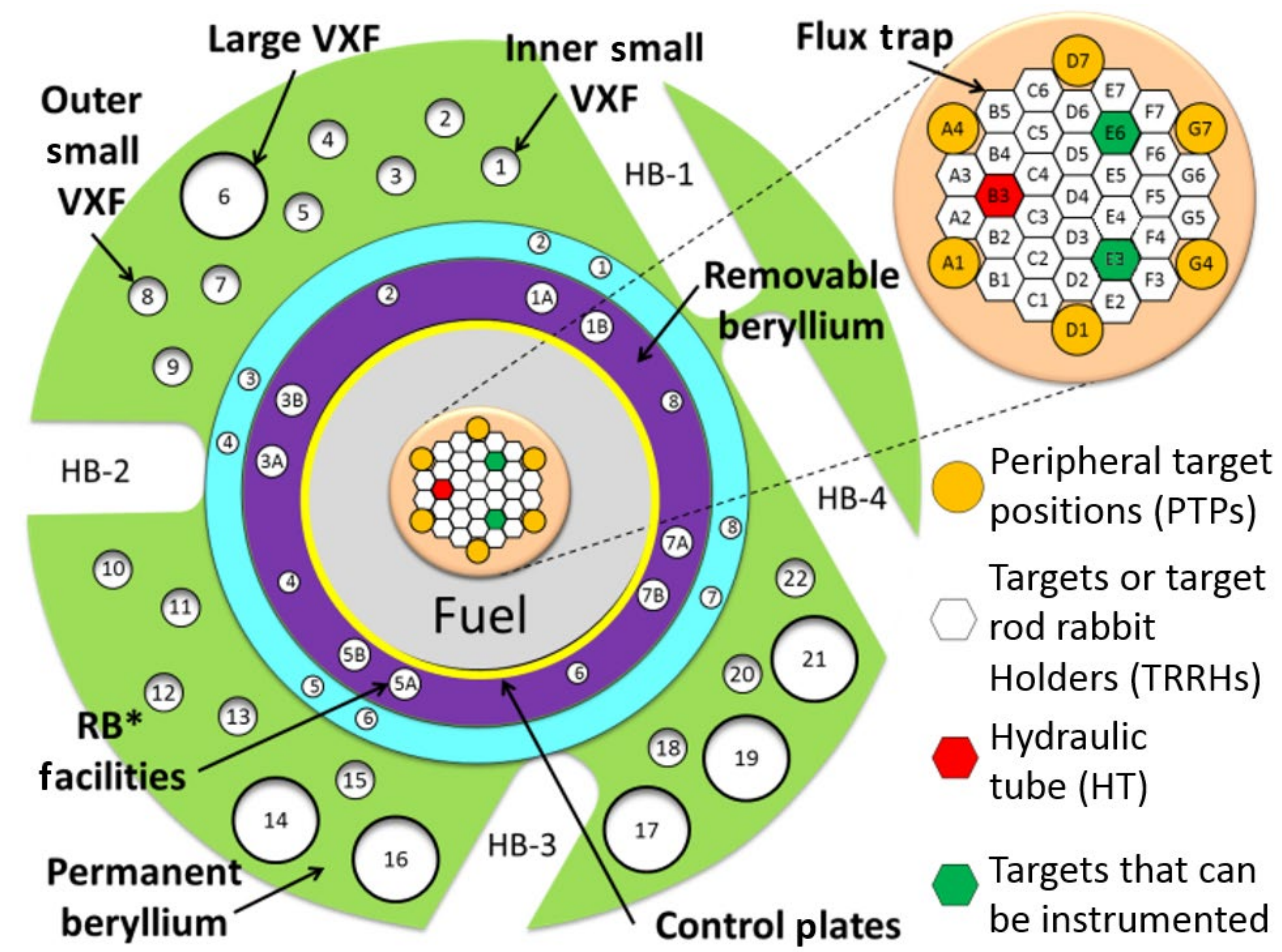

Figure 1. Schematic showing transverse section view of HFIR core, reflector, and experimental positions (not to scale) [4]

\section{HFIR IRRADIATION OF YTTRIUM HYDRIDE DISKS}

\subsection{BACKGROUND}

Transition metals are known to absorb large quantities of hydrogen to form solid solutions at low hydrogen content, and the metals for hydrides at higher hydrogen content. The densities of hydrogen atoms in some transition metal hydrides are greater than those in water or in liquid hydrogen, enabling a variety of applications within nuclear and non-nuclear systems. Hydrogen is an outstanding moderator because of its substantial equivalence in mass to the neutron and its acceptably high neutron scattering cross section. This characteristic is useful for bringing the incident neutron energy to a level at which it has a greater probability of interacting with other fissile, fertile, and neutron-control atoms. For example, zirconium hydride $\left(\mathrm{ZrH}_{\mathrm{x}}\right)$ is frequently used as a high-performance moderating material in advanced reactors. Examples include the Systems Nuclear Auxiliary Power (SNAP) Program [5], Training, Research, Isotopes, General Atomic (TRIGA) research reactors [6], and nuclear thermal propulsion reactors [7]. However, the application of $\mathrm{ZrH}_{\mathrm{x}}$ to nuclear systems required careful management of the moderator temperature to avoid hydrogen desorption at elevated temperatures. In contrast, yttrium hydride $\left(\mathrm{YH}_{\mathrm{x}}\right)$ is more attractive for such applications due to its significantly lower equilibrium hydrogen partial pressure at elevated temperatures. For example, the equilibrium hydrogen pressure for $\mathrm{YH}_{1.6}$ at $900^{\circ} \mathrm{C}$ is only 8.8 torr [8] compared to an expected value of $3.3 \times 10^{3}$ torr for $\mathrm{ZrH}_{1.6}$ at the same temperature. 
The successful deployment of $\mathrm{YH}_{\mathrm{x}}$ as a high-temperature moderator in advanced reactors requires a robust understanding of its response to neutron irradiation. However, the database of the physical and thermomechanical properties of neutron-irradiated $\mathrm{YH}_{\mathrm{x}}$ is not yet available, so a campaign to irradiate $\mathrm{YH}_{\mathrm{x}}$ in HFIR was initiated in FY19 under the TCR program. The current results of these efforts are reported below. Properties being investigated include swelling, heat capacity, thermal diffusivity, thermal expansion, hardness, and fracture toughness. Furthermore, as many of the properties are known to be strongly dependent on hydrogen content, both $\mathrm{YH}_{1.5}$ and $\mathrm{YH}_{1.7}$ are included in testing.

\subsection{IRRADIATION CAPSULE DESIGN CONCEPT}

In this experiment, the rabbit capsule is loaded with a sealed molybdenum holder that contains the diskshaped $\mathrm{YH}_{\mathrm{x}}$ specimens and their associated components, as shown in Figure 2. On each side of the holder's interior, eight $6 \mathrm{~mm}$ diameter specimens are lined with four silicon carbide $(\mathrm{SiC})$ pieces that are $24 \mathrm{~mm}$ long. These are separated by two additional pieces of SiC retainers that are $48 \mathrm{~mm}$ long and two thin $\mathrm{SiC}$ retainer springs bent to press the specimen assemblies to the holder wall. Four SiC slabs $24 \mathrm{~mm}$ in length serving as thermometry are placed between the sample layer and the SiC retainers. The holder features welded end caps on each side to mitigate the potential of hydrogen release from the sample holder to the external Al housing, thus minimizing the amount of hydrogen diffusing into HFIR coolant. Molybdenum was specifically chosen due to its performance at high temperatures, frequency of use in similar experiments, and its anticipated resistance to hydrogen chemical interactions and leakage.

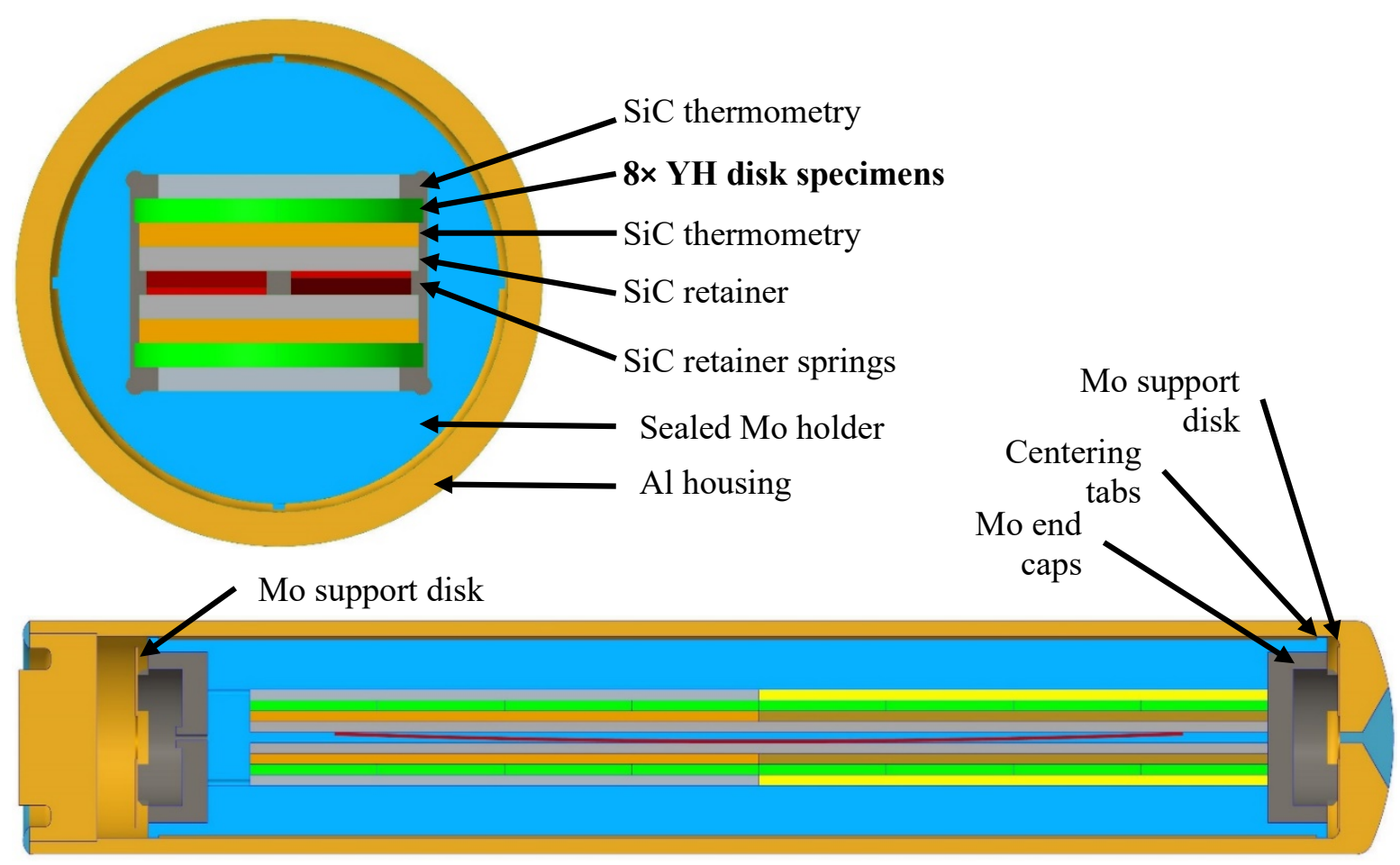

Figure 2. Design of YHx irradiation capsule. 
This experiment will consist of twelve rabbits in total, representing two hydrogen concentrations of $\mathrm{YH}_{1.5}$ and $\mathrm{YH}_{1.7}$, two design temperatures of 600 and $900^{\circ} \mathrm{C}$, and three specimen doses of $0.1,1$, and $2 \mathrm{dpa}$. The test matrix is shown in Table 1. This approach requires placing eight rabbits in the hydraulic tube for partial cycles and four in the permanent facilities for a single cycle. It is anticipated that these experiments will be at the centerline of the reactor or offset from the centerline by one position. To accomplish this, neutronic, thermal, and leak calculations must be performed to determine the design parameters and to ensure that conditions stay within their respective safety limits. The equilibrium pressure of hydrogen due to desorption is as follows:

- $\mathrm{YH}_{1.5}$ at $600^{\circ} \mathrm{C}: 1.8 \times 10^{-3}$ torr

- $\mathrm{YH}_{1.7}$ at $600^{\circ} \mathrm{C}: 3.4 \times 10^{-3}$ torr

- $\mathrm{YH}_{1.5}$ at $900^{\circ} \mathrm{C}: 6.3$ torr

- $\mathrm{YH}_{1.7}$ at $900^{\circ} \mathrm{C}: 48$ torr

Table 1. Irradiation test matrix

\begin{tabular}{|c|c|c|c|}
\hline $\begin{array}{l}\text { Capsule } \\
\text { ID }\end{array}$ & $\begin{array}{l}\text { Irradiation } \\
\text { temperature }\end{array}$ & Dose (dpa) & Materia \\
\hline YHXT01 & \multirow{3}{*}{$600^{\circ} \mathrm{C}$} & 0.1 & \multirow{6}{*}{$\mathrm{YH}_{1.5}$} \\
\hline YHXT02 & & 1 & \\
\hline YHXT03 & & 2 & \\
\hline YHXT04 & \multirow{3}{*}{$900^{\circ} \mathrm{C}$} & 0.1 & \\
\hline YHXT05 & & 1 & \\
\hline YHXT06 & & 2 & \\
\hline YHXT07 & \multirow{3}{*}{$600^{\circ} \mathrm{C}$} & 0.1 & \multirow{6}{*}{$\mathrm{YH}_{1.7}$} \\
\hline YHXT08 & & 1 & \\
\hline YHXT09 & & 2 & \\
\hline YHXT10 & \multirow{3}{*}{$900{ }^{\circ} \mathrm{C}$} & 0.1 & \\
\hline YHXT11 & & 1 & \\
\hline YHXT12 & & 2 & \\
\hline
\end{tabular}

\subsection{NEUTRONICS ANALYSIS}

No historical reference exists for irradiation of $\mathrm{YH}_{\mathrm{x}}$ materials in HFIR, and its behavior and performance in the reactor cannot be bound by existing safety-basis calculations with adequate confidence. Therefore, this gap requires a dedicated neutronic analysis of the irradiation capsule to assess nuclear heat generation in the samples and capsule structural components under anticipated operating conditions. This will enable thermal design studies of the capsule, as well as the ultimate approval of the experiment for insertion in HFIR. Heat is generated in the experiment capsule due to several contributions: fission neutrons from the HFIR fuel, prompt photons from fission in the fuel and $(n, \gamma)$ reactions throughout the core, delayed photons from the decay of fission products accumulated in the fuel, $\alpha$ and $\beta$ decay heat due to activation of capsule components under irradiation, and activation photons due to the decay of activation products in the capsule. Each source requires distinct neutronic treatment. 
Standard safety-basis Monte Carlo N-Particle 5 (MCNP5) models of the HFIR core with cycle 400 experiment loading conditions at beginning and end of cycle (BOC/EOC) provide templates for the neutronics calculations carried out in this work. These models are modified to include the geometry and materials of the experiment capsule as described above; particular care is taken in these models to appropriately capture thermal neutron scattering physics in $\mathrm{YH}_{\mathrm{x}}$ [9]. To cover a breadth of anticipated conditions to which the capsule may be exposed in the HFIR flux trap target (FTT) region, the capsule is modeled in three different peripheral target positions (PTPs), three different outer ring positions, and the hydraulic tube (HT). In all cases, the capsule is centered about the axial midplane of the core to maximize incident neutron and photon flux, thereby yielding bounding design- and safety-basis heat generation rates.

Heat generation from fission neutrons and prompt photons can be assessed from a single MCNP run in each FTT position in criticality mode with neutron and photon tracking enabled. Tallies are constructed to record the statistically estimated energy deposited by neutrons and photons in each capsule component. A separate MCNP calculation is run with a fixed photon source reflecting the photon emission rate and spectrum due to fission products accumulated in the HFIR fuel; this calculation determines heating contributed by these delayed photons. As MCNP is only capable of static transport calculations, additional tools are needed to assess decay heat, namely the COUPLE and ORIGEN modules of the SCALE code system. Fine-group neutron flux spectra are assessed for each capsule component in the initial MCNP run which are then passed to the COUPLE cross section processing module to generate reaction cross sections that are neutronically consistent across codes. These cross sections are then used for irradiation calculations using ORIGEN for each capsule component in each FTT position to determine locally deposited $\alpha$ and $\beta$ decay heat. ORIGEN also outputs the spectrum and emission rates of decay photons from each activated material. This information is used to define a fixed photon source for a final MCNP calculation to determine the heat generation resulting from these photons.

Results from each of these contributions are summed for each component in each FTT position to determine design-basis heat generation rates for subsequent use in thermal analyses. Determination of safety-basis heat generation rates requires further manipulation that is relegated to this calculation document for the sake of concise presentation. Instead, Table 2 below shows the bounding design-basis heat generation results achieved in the A1 PTP position with $\mathrm{YH}_{1.7}$.

Table 2. Bounding Design-Basis Nuclear Heat Generation

\begin{tabular}{lcc}
\hline Component & Heat generation $(\mathbf{W} / \mathbf{g})$ & Relative error \\
\hline TM-1 & 30.9 & 0.0037 \\
TM-1 & 31.0 & 0.0037 \\
TM-1 & 31.3 & 0.0037 \\
TM-1 & 31.3 & 0.0036 \\
TM-2 & 30.8 & 0.0034 \\
TM-2 & 30.8 & 0.0034 \\
TM-2 & 31.1 & 0.0034 \\
TM-2 & 31.0 & 0.0034 \\
Retainer & 30.9 & 0.0024 \\
Retainer & 30.9 & 0.0024 \\
Spring & 31.2 & 0.0044 \\
Spring & 30.6 & 0.0043 \\
Sample group 1 & 45.2 & 0.0033 \\
Sample group 2 & 45.3 & 0.0033 \\
Sample group 3 & 45.3 & 0.0032
\end{tabular}




\begin{tabular}{lll} 
Sample group 4 & 45.7 & 0.0032 \\
Insulator & 32.4 & 0.0077 \\
Insulator & 32.4 & 0.0079 \\
Holder & 46.6 & 0.0010 \\
Housing & 32.2 & 0.0023 \\
\hline
\end{tabular}

\subsection{CAPSULE THERMAL ANALYSIS}

To determine the temperature distribution in the assembly, the ANSYS finite element software is utilized with custom, user-defined macros and inputs from the neutronics analysis. Descriptions of these macros can be found in Design and Analysis Calculation (DAC) 11-13-ANSYS02, Rev. 6, which is available by request [10]. Examples include algorithms that calculate the properties of gas mixtures [11] and approximate the effect of thermal expansion without requiring a coupled structural analysis [12]. Likewise, temperature-dependent (and in the case of $\mathrm{SiC}$, dose-dependent) material properties are calculated using a database of DACs maintained by the ORNL Nuclear Experiments and Irradiation Testing Group. These properties are obtained from CINDAS [13], MatWeb [14], and a variety of literature sources. Table 3 lists previously approved DACs used in this calculation.

Table 3. $\mathrm{YH}_{\mathrm{x}}$ rabbit materials and material property references

\begin{tabular}{lcc}
\hline Part & Material & Reference DAC \\
\hline Holder, disks & Molybdenum & DAC-10-11-PROP_MOLY [15] \\
Housing & Aluminum & DAC-10-03-PROP_AL6061 [16] \\
Specimens & Yttrium hydride & DAC-19-03-PROP_YHX [17] \\
$\begin{array}{l}\text { Thermometry, } \\
\text { springs }\end{array}$ & Silicon carbide & DAC-10-06-PROP_SIC(IRR) [18] \\
\hline
\end{tabular}

For the specimens in particular, a new DAC was written to determine the properties of the hydride material. This macro accepts a given hydrogen content and calculates the phase and properties of the material at several reference temperatures. The phase diagram used is recommended by Khatamian and Manchester [19], while thermal and structural properties are from experiments by Ito et al. and Setoyama et al., respectively [20] [21]. The remaining values can be found in commonly available sources [14] [22]. For safety calculations, the macro can also be set to provide conservative values for each property. Other inputs, such as the convection boundary conditions for each case and the axial power profile, can be found in Table 4.

Table 4. $\mathbf{Y H}_{\mathrm{x}}$ rabbit thermal boundary conditions [23] [24] [25]

\begin{tabular}{lcccc}
\hline Parameter & Unit & Design & LCS* & 0.5 gpm flow \\
\hline Convective coefficient & $\mathrm{kW} / \mathrm{m}^{2} \cdot \mathrm{K}$ & $31.6-48.4$ & 22.5 & 4.968 \\
Bulk coolant temperature & ${ }^{\circ} \mathrm{C}$ & $52-54$ & 77 & 182 \\
Power scaling factor & --- & 1.03 & 1.30 & 1.03 \\
Power profile & $\mathrm{cm}$ & $29.70,30.39$ & Flat & Flat \\
\hline *Limiting condition scenario & & & &
\end{tabular}


When considering all potential placement configurations, this experiment represents 48 possible scenarios to analyze and optimize. To aid in managing this, the model is parameterized and used to construct a response surface with the ANSYS DesignXplorer software package. This is a fitted model of the system's response to many inputs, allowing for the quick, accurate estimation of results. This in turn enables optimization studies which are used to fine-tune the design to enhance performance and minimize the number of parts required.

Temperature profiles for specimens and rabbit internals are presented in Figure 3 for the illustrative case of $\mathrm{YH}_{1.7}$ specimens in the centerline position of a target rod rabbit holder, with an average specimen temperature of $896^{\circ} \mathrm{C}$ compared to a design temperature of $900^{\circ} \mathrm{C}$ and an overall maximum temperature of $914^{\circ} \mathrm{C}$. To achieve this, the holder has an outer diameter (OD) of $9.18 \mathrm{~mm}$, and the housing is filled with a mixture of $64 \%$ helium and $36 \%$ argon. This case is one of many that could be generated by the response surface of the system, which is shown in Figure 4 for the average specimen temperature as a function of its two most sensitive parameters: the diameter of the holder and the fill gas composition. Other parameters analyzed include the design temperature, the hydrogen concentration in the specimens, the dose to the specimens, the irradiation location, and the axial position of the rabbit in the reactor. Initial safety calculations show the margin to melt in all components: ongoing is in process to confirm this finding. The impact of the hydrogen content on the thermal analysis of $\mathrm{YH}_{\mathrm{x}}$ capsules is very limited due to the small difference in thermal conductivity. Detailed images for the $600^{\circ} \mathrm{C}$ irradiation capsule design is omitted here. 


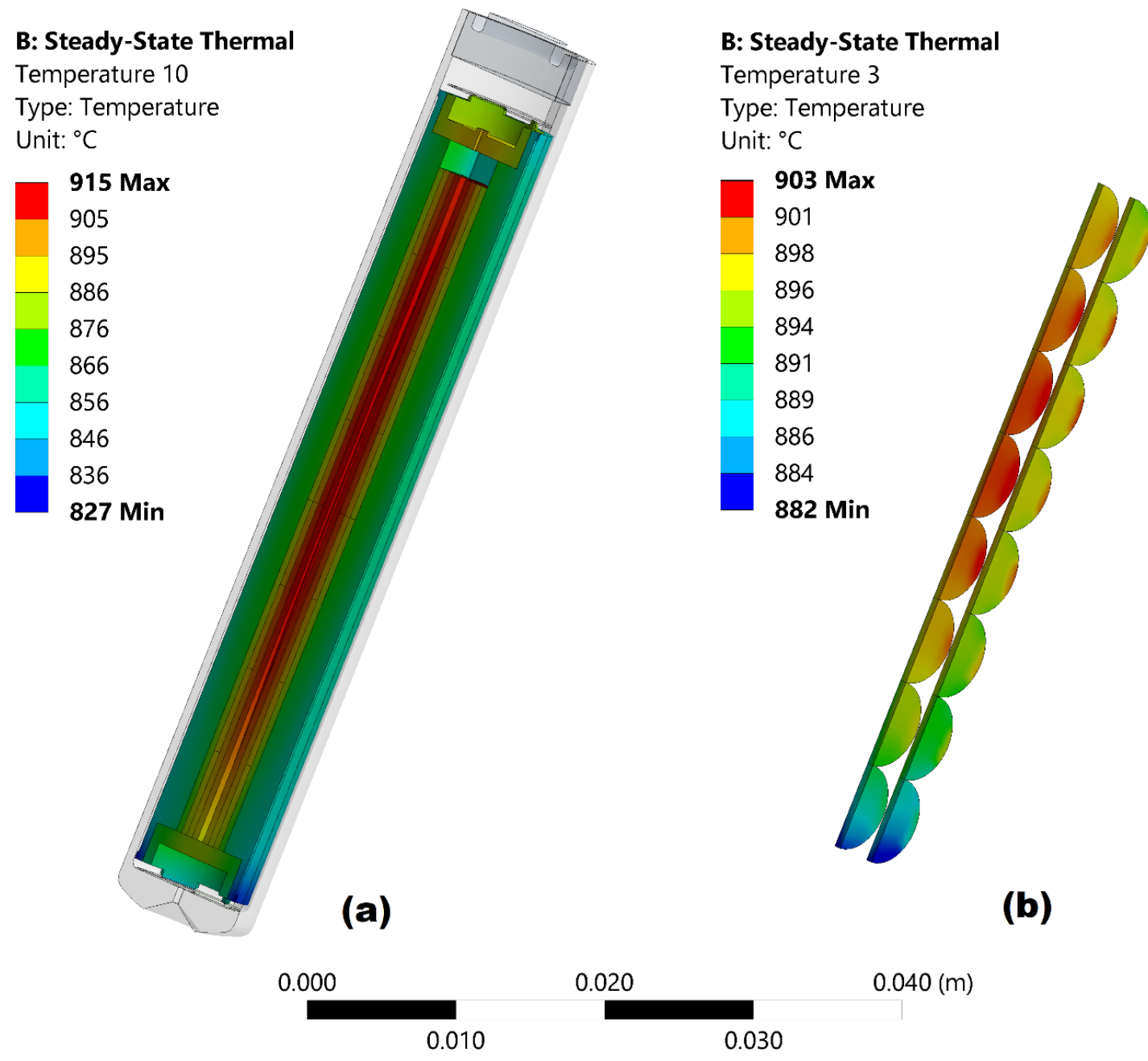

Figure 3. Temperatures in (a) the rabbit internals and (b) specimens for a $9.18 \mathrm{~mm}$ diameter holder and $64 \%$ helium $+36 \%$ argon fill gas for the $\mathrm{YH}_{1.7}$ irradiation capsule with a targeted temperature of $900^{\circ} \mathrm{C}$. 


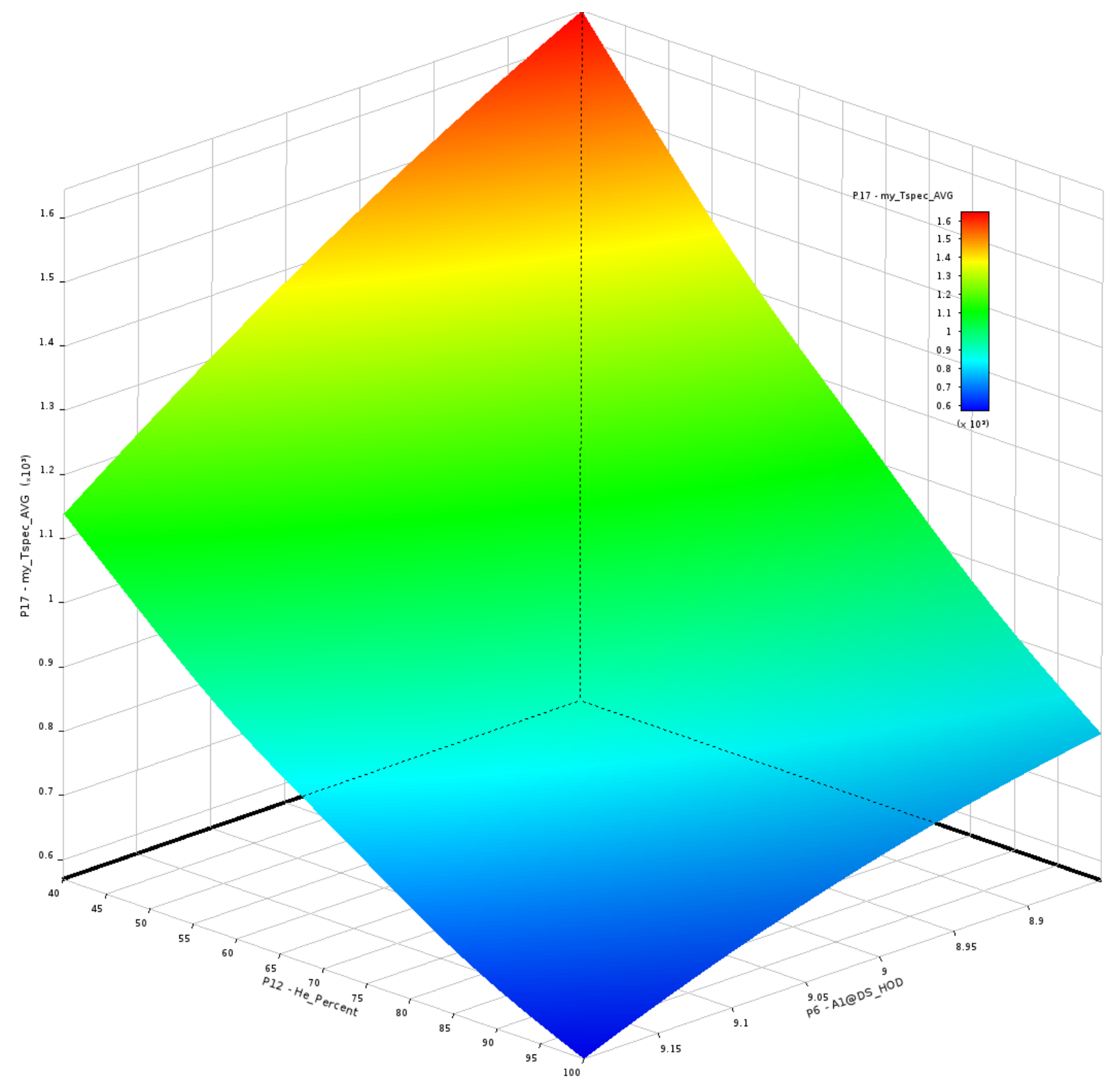

Figure 4. $\mathrm{YH}_{\mathrm{x}}$ specimen average temperature as a function of holder diameter and helium concentration in the housing (Vertical axis is temperature in ${ }^{\circ} \mathrm{C}$; left axis is He gas fraction (\%), and right axis is holder diameter in $\mathbf{m m}$ ). 


\section{HFIR IRRADIATION OF 3D PRINTED SIC DISKS IRRADIATIONS}

\subsection{BACKGROUND}

Advanced manufacturing of $\mathrm{SiC}$ (powder binderjet) combined with chemical vapor infiltration (3Dprinted SiC-CVI) provides an attractive level of freedom in component design due to the hightemperature performance of these materials and allowances for geometrical complexity. 3D-printed SiCCVI results in a high purity material with crystallinity which will likely provide tolerance to in-core atom displacement damage and resistance to thermal creep similar to that provided by bulk reference material (chemical vapor deposited [CVD] SiC). A HFIR irradiation is planned for FY20 with 3D-printed SiCCVI disks and bulk CVD-SiC to evaluate the material's property response to temperature and irradiation dose, including various printing techniques and powders.

\subsection{EXPERIMENT DESIGN}

The overall design concept is summarized in Figure 5. The outer containment for all experiments is the rabbit capsule housing, which is directly cooled on the outer surface by HFIR's primary coolant. These rabbits include 32 disk specimens that are nominally $0.5 \mathrm{~mm}$ thick. There are two sets of 16 specimens located on either side of the center retainer spring. Each set has 2 layers of 8 specimens stacked between the inner and outer TMs. The TMs are SiC slabs that are evaluated using dilatometry post-irradiation to confirm the irradiation temperature [26]. The SiC retainer specimens keep the internal contents of the experiment pressed against the inner walls of the specimen holder. Insulator discs at the top and bottom of the assembly reduce axial heat losses. Temperature is controlled by varying the concentration of a helium/argon gas mixture and the size of the gas gap between the holder and the housing. Varying the gas mixture changes the effective thermal conductivity of the gas gap. Centering thimbles are inserted into the ends of the specimen holder to keep it centered within the rabbit capsule, ensuring a constant gas gap around the perimeter of the specimen holder.

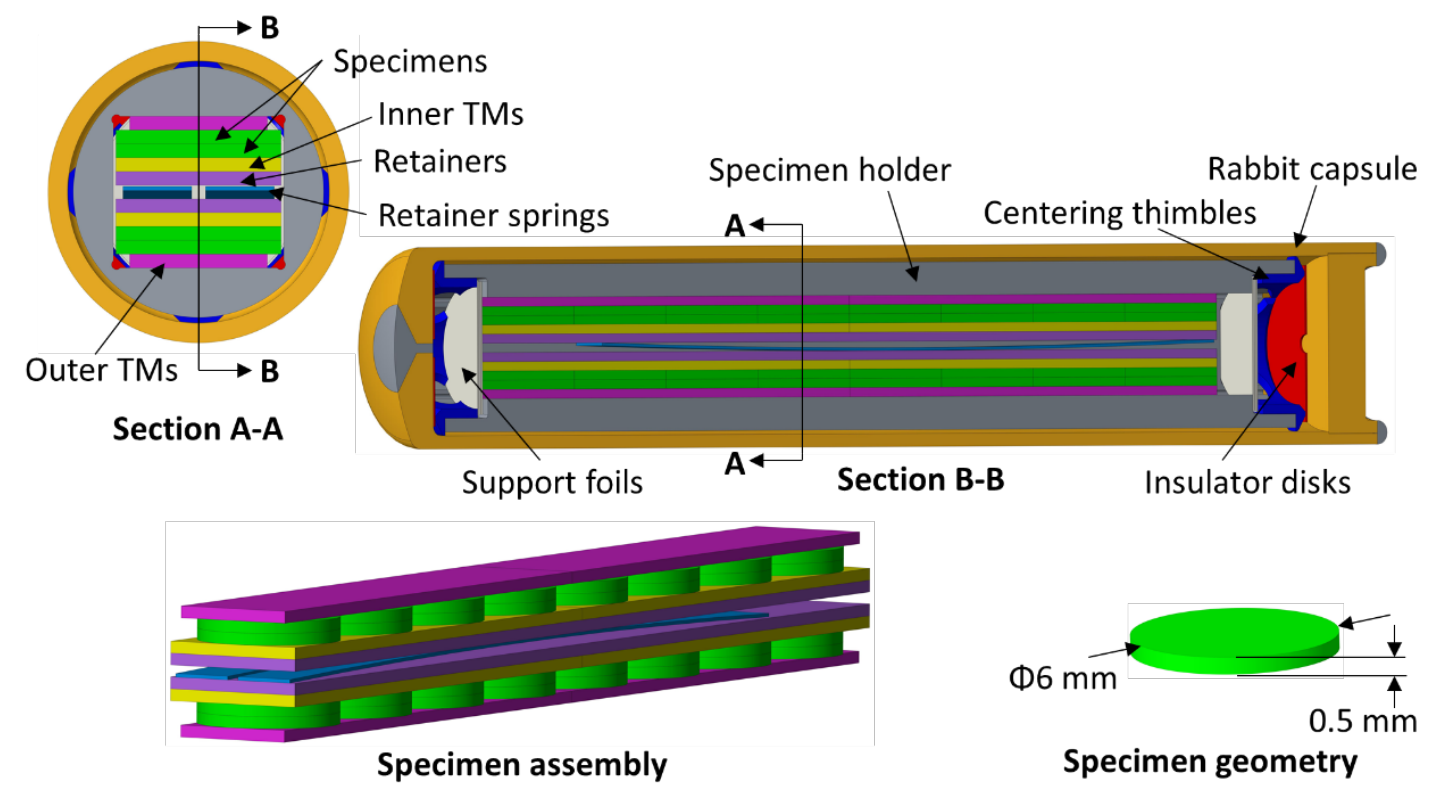

Figure 5. Schematic showing the irradiation capsule design. 


\subsection{CAPSULE THERMAL ANALYSIS}

The computer-aided design (CAD) models were imported into the ANSYS finite element software package for thermal analysis to ensure that the specimens would be irradiated at the desired temperatures. This is accomplished by calculating the gamma heating generated within the capsule components and sizing an insulating gas gap through which the internal heat must pass before being rejected to the HFIR primary coolant, which flows around the outer surface of the capsules. Similar approaches have been used for previous HFIR irradiation experiments [27] [28] [29] [30] [31] [32] [33] [34]. For the experiments described herein, the variables adjusted to achieve the design temperatures are the size and composition of the gas gap between the specimen holder and the rabbit housing, as well as the specimen holder material (different materials have different gamma heating rates).

Figure 6 through Figure 8 show the temperature contours predicted by the thermal analyses for nominal specimen temperatures of 400,650 , and $900^{\circ} \mathrm{C}$, respectively. These temperatures are for capsules positioned in TRRH position 6 within the HFIR flux trap. Axial positions are numbered 1 through 7 within the TRRHs from the bottom to the top of the core. Position 4 is closest to the core's midplane, and position 6 is centered $\sim 12.7 \mathrm{~cm}$ above the core's midplane.

\section{(a) Capsule assembly}

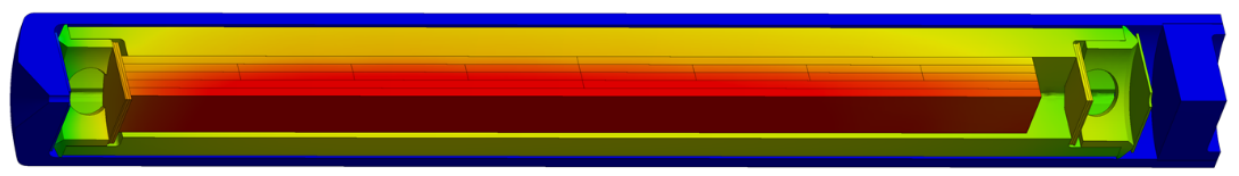

(b) Specimens

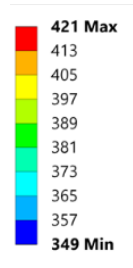

\section{(c) Passive temperature monitors}

Figure 6. Predicted temperature contours $\left(\right.$ in ${ }^{\circ} \mathrm{C}$ ) for the nominally $400^{\circ} \mathrm{C}$ design with $1 / 4$-symmetry showing (a) the entire capsule assembly, (b) the specimens, and (c) the passive temperature monitors. 
(a) Capsule assembly

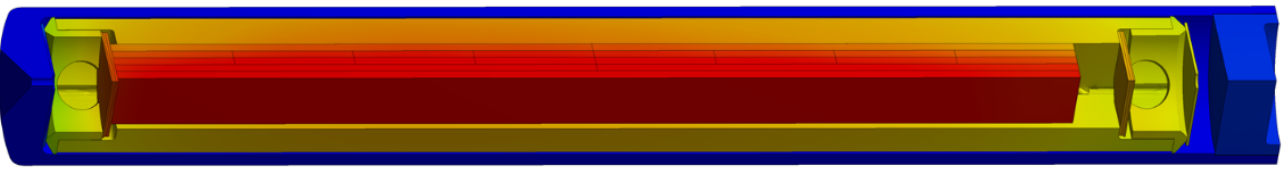

(b) Specimens

\section{(c) Passive temperature monitors}

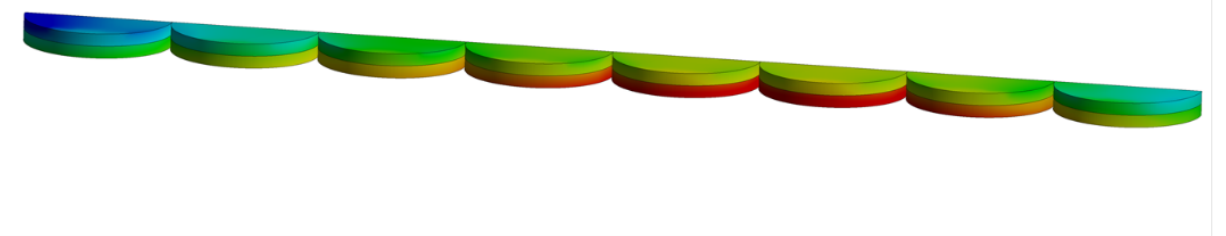

Figure 7. Predicted temperature contours (in ${ }^{\circ} \mathrm{C}$ ) for the nominally $650^{\circ} \mathrm{C}$ design with 1/4-symmetry showing (a) the entire capsule assembly, (b) the specimens, and

(c) the passive temperature monitors. 
(a) Capsule assembly
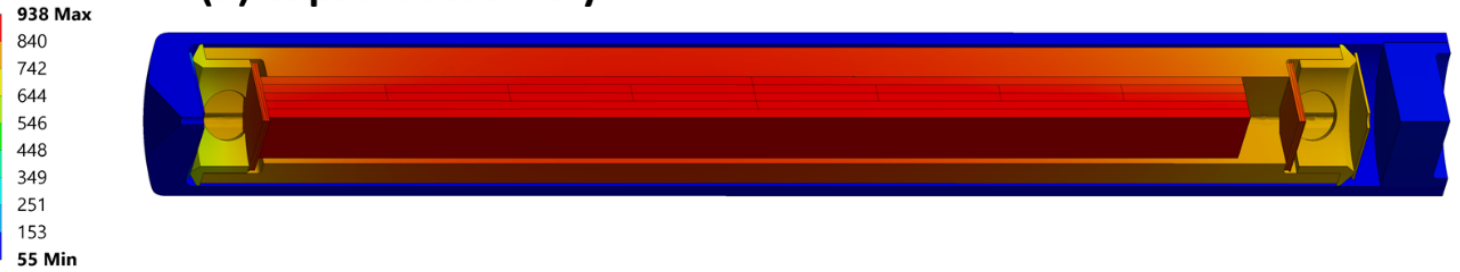

(b) Specimens
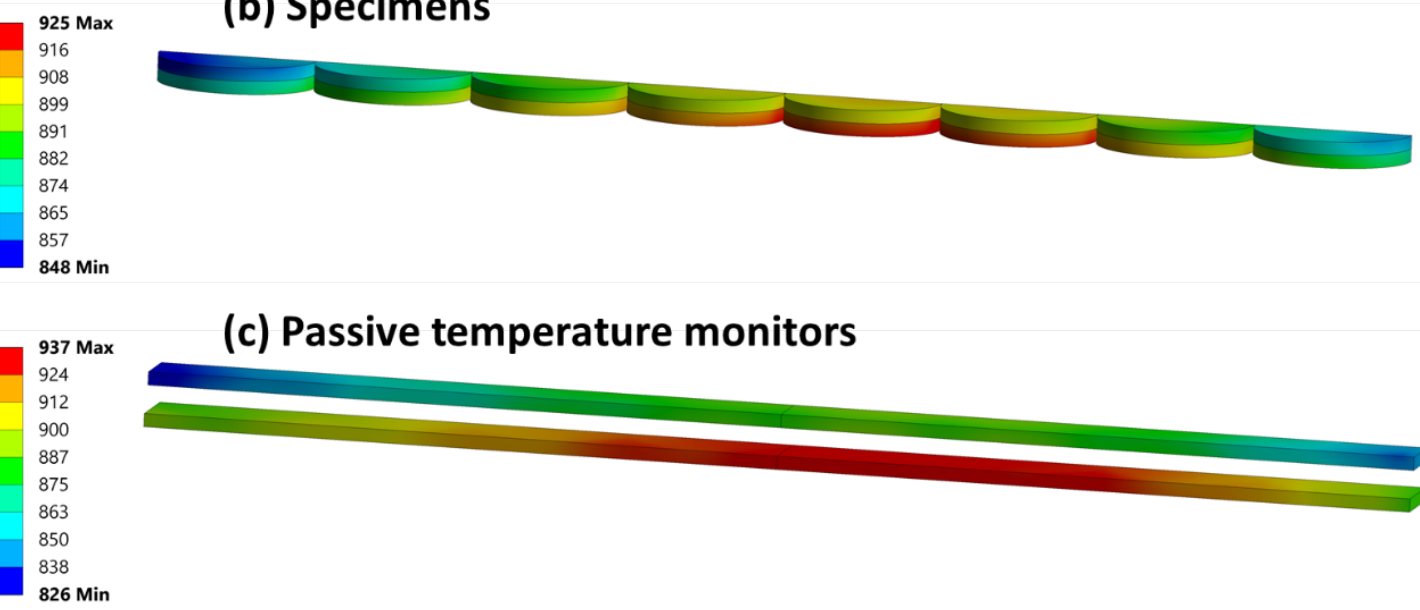

\section{(c) Passive temperature monitors}

Figure 8. Predicted temperature contours (in ${ }^{\circ} \mathrm{C}$ ) for the nominally $900^{\circ} \mathrm{C}$ design with $1 / 4$-symmetry showing (a) the entire capsule assembly, (b) the specimens, and

(c) the passive temperature monitors.

The inner and outer TMs provide bounds on the specimen temperatures, with the inner TM temperatures being closer to the temperature of the inner specimens, and the outer TM temperatures being closer to the temperature of the outer specimens. Table 5 summarizes average, minimum, and maximum temperatures for all important components, in addition to other design parameters such as the irradiation position, holder material, fill gas, and size of the primary gas gap. The irradiation positions include TRRH positions, as well as PTPs, which are numbered axially 1 through 8 from the bottom to the top of core. Position 5 is closest to the axial midplane. The lower temperature capsules use a vanadium alloy holder. The higher temperature capsules use a niobium holder with $1 \%$ zirconium. Simulations are performed for multiple positions because it is not known at the time of the analysis which HFIR positions will be available when the capsules are inserted into the reactor. Analyzing for multiple positions increases the likelihood that the assembled capsules can be immediately inserted into the reactor. 
Table 5. Summary of component temperatures, irradiation position, holder material, fill gas, and cold gas gaps for $\mathrm{SiC}$ disk specimens

\begin{tabular}{|c|c|c|c|c|c|c|c|c|}
\hline \multirow{2}{*}{$\begin{array}{l}\text { Nominal } \\
\text { temperature }\end{array}$} & \multirow{2}{*}{ Position } & \multirow{2}{*}{$\begin{array}{l}\text { Holder } \\
\text { material }\end{array}$} & \multirow{2}{*}{ Fill gas } & \multirow{2}{*}{ Gas gap } & \multirow[b]{2}{*}{ Part } & \multicolumn{3}{|c|}{ Temperature $\left({ }^{\circ} \mathrm{C}\right)$} \\
\hline & & & & & & Average & Minimum & Maximum \\
\hline \multirow{6}{*}{$400^{\circ} \mathrm{C}$} & \multirow{3}{*}{ TRRH-6 } & \multirow{6}{*}{$\mathrm{V}-4 \mathrm{Cr} 4 \mathrm{Ti}$} & \multirow{6}{*}{$\mathrm{He}$} & \multirow{6}{*}{$170 \mu \mathrm{m}$} & Specimens & 395 & 349 & 421 \\
\hline & & & & & Inner TMs & 416 & 384 & 436 \\
\hline & & & & & Outer TMs & 364 & 314 & 385 \\
\hline & \multirow{3}{*}{ PTP-3 } & & & & Specimens & 401 & 343 & 429 \\
\hline & & & & & Inner TMs & 423 & 363 & 446 \\
\hline & & & & & Outer TMs & 368 & 315 & 391 \\
\hline \multirow{6}{*}{$650^{\circ} \mathrm{C}$} & \multirow{3}{*}{ TRRH-6 } & \multirow{6}{*}{$\mathrm{V}-4 \mathrm{Cr} 4 \mathrm{Ti}$} & \multirow{6}{*}{$\begin{array}{c}40.5 \% \mathrm{He} \\
59.5 \% \mathrm{Ar}\end{array}$} & \multirow{6}{*}{$135 \mu \mathrm{m}$} & Specimens & 650 & 599 & 679 \\
\hline & & & & & Inner TMs & 676 & 645 & 697 \\
\hline & & & & & Outer TMs & 614 & 561 & 636 \\
\hline & \multirow{3}{*}{ PTP-3 } & & & & Specimens & 658 & 591 & 690 \\
\hline & & & & & Inner TMs & 685 & 617 & 709 \\
\hline & & & & & Outer TMs & 619 & 560 & 644 \\
\hline \multirow{6}{*}{$900^{\circ} \mathrm{C}$} & \multirow{4}{*}{ TRRH-6 } & \multirow{6}{*}{$\mathrm{Nb}-1 \mathrm{Zr}$} & \multirow{6}{*}{$\begin{array}{c}40.5 \% \mathrm{He} \\
59.5 \% \mathrm{Ar}\end{array}$} & \multirow{6}{*}{$210 \mu \mathrm{m}$} & Specimens & 896 & 848 & 925 \\
\hline & & & & & Inner TMs & 916 & 885 & 937 \\
\hline & & & & & Outer TMs & 873 & 826 & 894 \\
\hline & & & & & Specimens & 916 & 840 & 952 \\
\hline & \multirow[t]{2}{*}{ РTP-3 } & & & & Inner TMs & 938 & 863 & 965 \\
\hline & & & & & Outer TMs & 892 & 818 & 921 \\
\hline
\end{tabular}

\section{HFIR IRRADIATION OF 3D PRINTED 316L}

\subsection{BACKGROUND}

Irradiated material property measurements of 3D printed materials are needed to support modeling efforts of TCR design concepts. TCR design concepts include 3D printed 316L stainless steel (SS316L) cans, lattice structures, and SS316L bristle or springs as core components. The yield stress as a function of temperature and dose for SS316L produced through additive manufacturing may differ from commonly produced SS316L [35]. Neutron irradiations will be performed to understand these differences using HFIR rabbit irradiation vehicles designed for tensile specimens and ORNL hot cell facilities' infrastructure to support mechanical testing and advanced characterization techniques.

\subsection{EXPERIMENT DESIGN}

This report details two capsule designs for two flexible capsule designs that accommodate either (1) the miniature tensile specimen, or (2) the M4CVN "bend bar" specimen. The flexible tensile design, referred to as the general tensile (GENTEN) capsule design, consists of three specimen holders stacked axially within the rabbit housing, as shown in Figure 9. The flexible bend bar design, referred to as the general bend (GENBEN) bar capsule design, has four M4CVNs contained within a single holder within the rabbit housing, as shown in Figure 10. 
The outer containment for the irradiation experiment is the rabbit capsule housing, which is directly cooled on the outer surface by HFIR's primary coolant. The specimens are placed in holders with ODs optimized to create gas gaps to control temperature performance. These holders can either be Al-6061 or molybdenum, for low and high target temperatures, respectively. Centering tabs with a slightly larger diameter are machined into the holders to keep the assemblies centered inside the housing and to maintain a constant gas gap between the holder and the housing. Stainless steel spring pins are used in the GENTEN design to hold the internal specimen in contact with the holder's inner walls. The chevrons are used as filler pieces that form a rectangular "coupon" shape to produce a uniform thermal load. Stainless steel wave springs are placed on the ends of the internal assembly between the housing and the holders to minimize axial heat loss.

The GENBEN design uses molybdenum wires to ensure that the specimens remain captured in the holder. The $\mathrm{SiC}$ spring ensures that the specimens remain in contact with the holder wall, also maintaining constant heat transfer. Stainless steel liners are used to insulate the specimens from the high thermally conductive holder. This feature is meant to reduce thermal gradients in the specimen. Stainless steel wave springs are also used in the bend bar design to isolate the holder from the capsule's ends and to minimize axial heat loss.

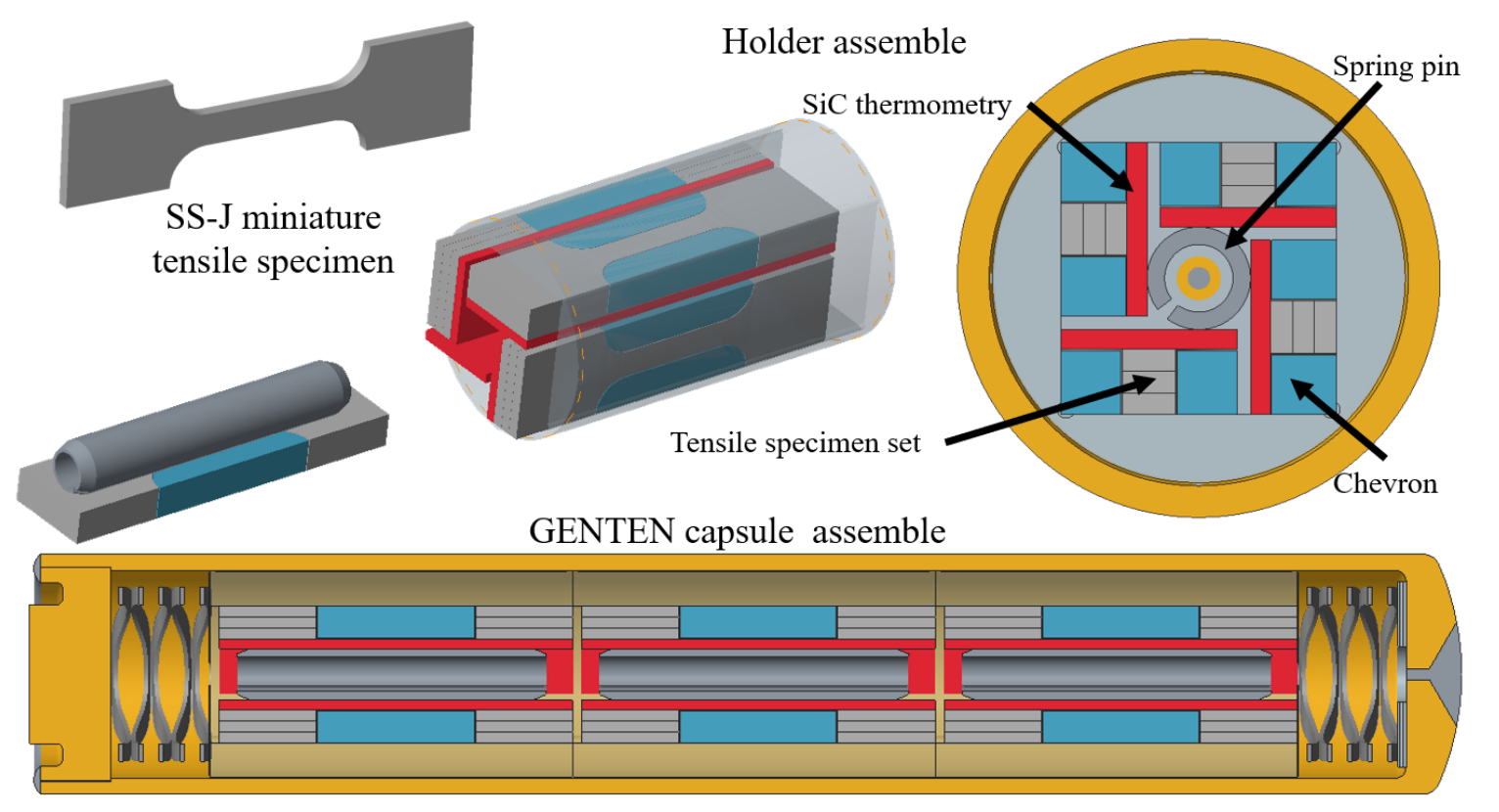

Figure 9. Section view of the GENTEN capsule design concept. 


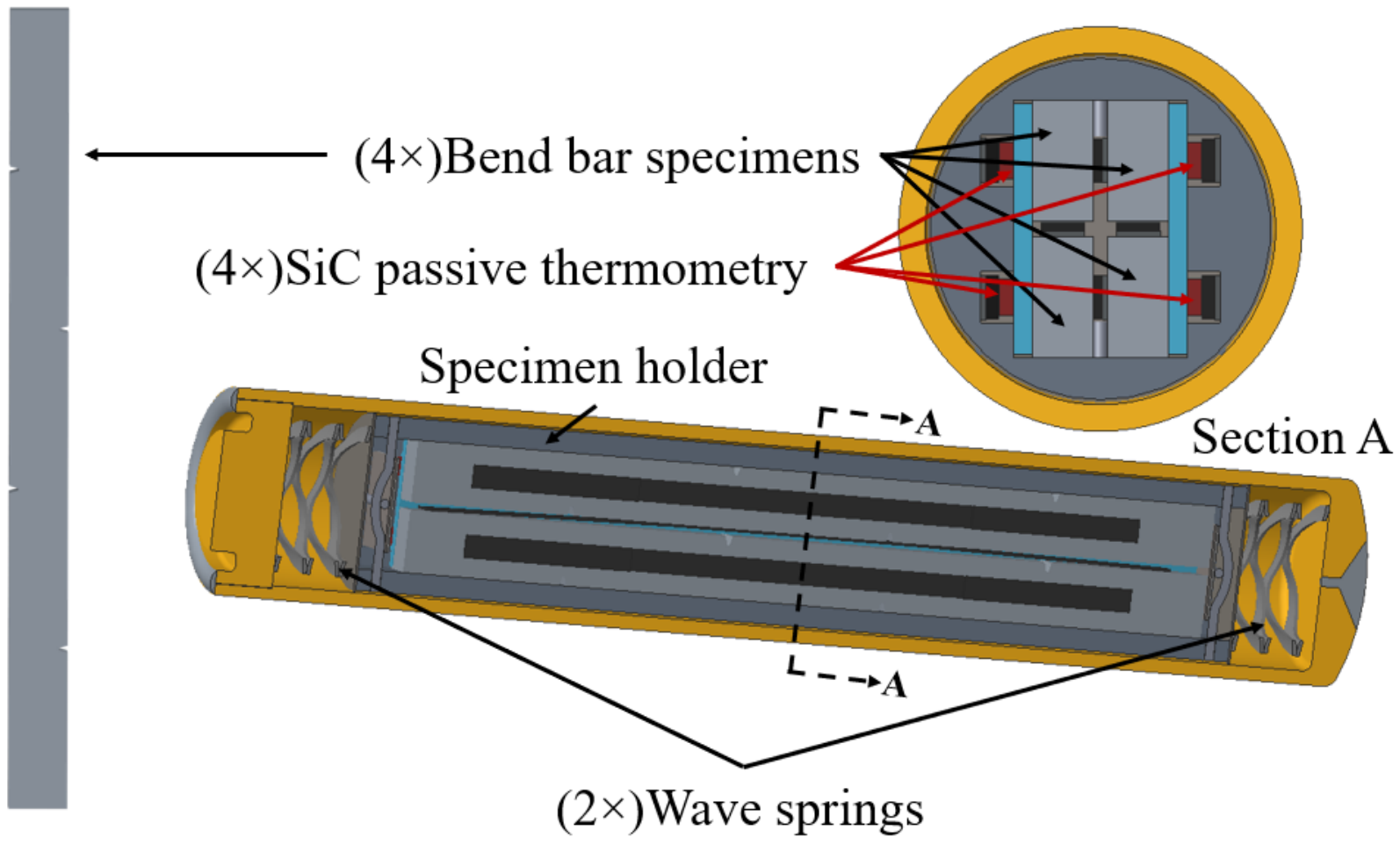

Figure 10. Section view of the GENBEN capsule showing the design concept.

\subsection{CAPSULE THERMAL ANALYSIS}

ANSYS finite element analysis software was used to predict temperature distributions inside the experiments. These analyses use material-dependent heat generation rates (heat per unit mass) as inputs; these rates were calculated from previously determined neutronics analyses. CAD models are imported into ANSYS and are used to perform thermal analyses and to optimize gas gap dimensions. Convection boundary conditions are applied to the outer surface of the housing. The heat generation rates vary in each irradiation location and as a function of axial distance from the reactor core midplane. As shown in Figure 1, multiple irradiation facilities are designated in the HFIR flux trap. These various degrees of freedom for analysis inputs can create large numbers of single irradiation conditions. These GENTEN and GENBEN designs are intended to be easily deployed throughout the flux trap, but analyzing all these cases explicitly is impractical. Therefore, a series of surface response calculations was performed for these two capsule designs. This approach effectively maps the target temperature design space for a given set of conditions.

The GENTEN and GENBEN designs were set up to achieve target temperatures ranging from 200 $1,000^{\circ} \mathrm{C}$ to be available for irradiation within the TRRH, PTP, and HT irradiation facilities. Varying the holder's OD was not sufficient to achieve this broad temperature range. Further degrees where established, including holder material and capsule elemental fill gas, to provide the remaining flexibility needed to map out the full temperature range. Al-6061 and molybdenum were selected as holder materials because they are very stable under neutron irradiation. Al-6061 is intended for specimen target temperatures below $400^{\circ} \mathrm{C}$ because of its low melting point, and molybdenum is used for all other conditions. Likewise, helium backfill gas is used for designs with specimen target temperatures below $\sim 600^{\circ} \mathrm{C}$, and neon is used for all other conditions. 
The full list of design inputs for the surface response mapping analysis is as follows:

- Flux trap axial position (1-7) and thermal hydraulic boundary conditions,

- Material specific heat generation rates

- Holder material (either Al-6061 or molybdenum

- Fill gas composition (either helium or neon)

- Holder diameter $(9.15-9.45 \mathrm{~mm})$

Representative sets of surface response maps for both the GENTEN and GENBEN designs placed in the TRRH facility can be seen in Figure 11 and Figure 12, respectively. The legend indicates XX-YYTRRHN, where $\mathrm{XX}$ is the holder material, $\mathrm{YY}$ is the fill gas, and $\mathrm{N}$ is the axial position of the capsule numbered from bottom (1) to top (7), with position 4 located at the vertical midplane of the core. This tool allows for specific capsule designs to be chosen from a table of data based on parameters such as target temperature and HFIR core availability. Furthermore, safety basis calculations have been produced and approved to bound these designs. Currently, GENTEN is approved for specimen target temperatures less than $1,000^{\circ} \mathrm{C}$ in the PTP and TRRH facilities, and temperatures less than $650^{\circ} \mathrm{C}$ are approved in the HT facility. The GENBEN design is approved for specimen target temperatures of less than $1,000^{\circ} \mathrm{C}$ in the PTP and TRRH facilities only.

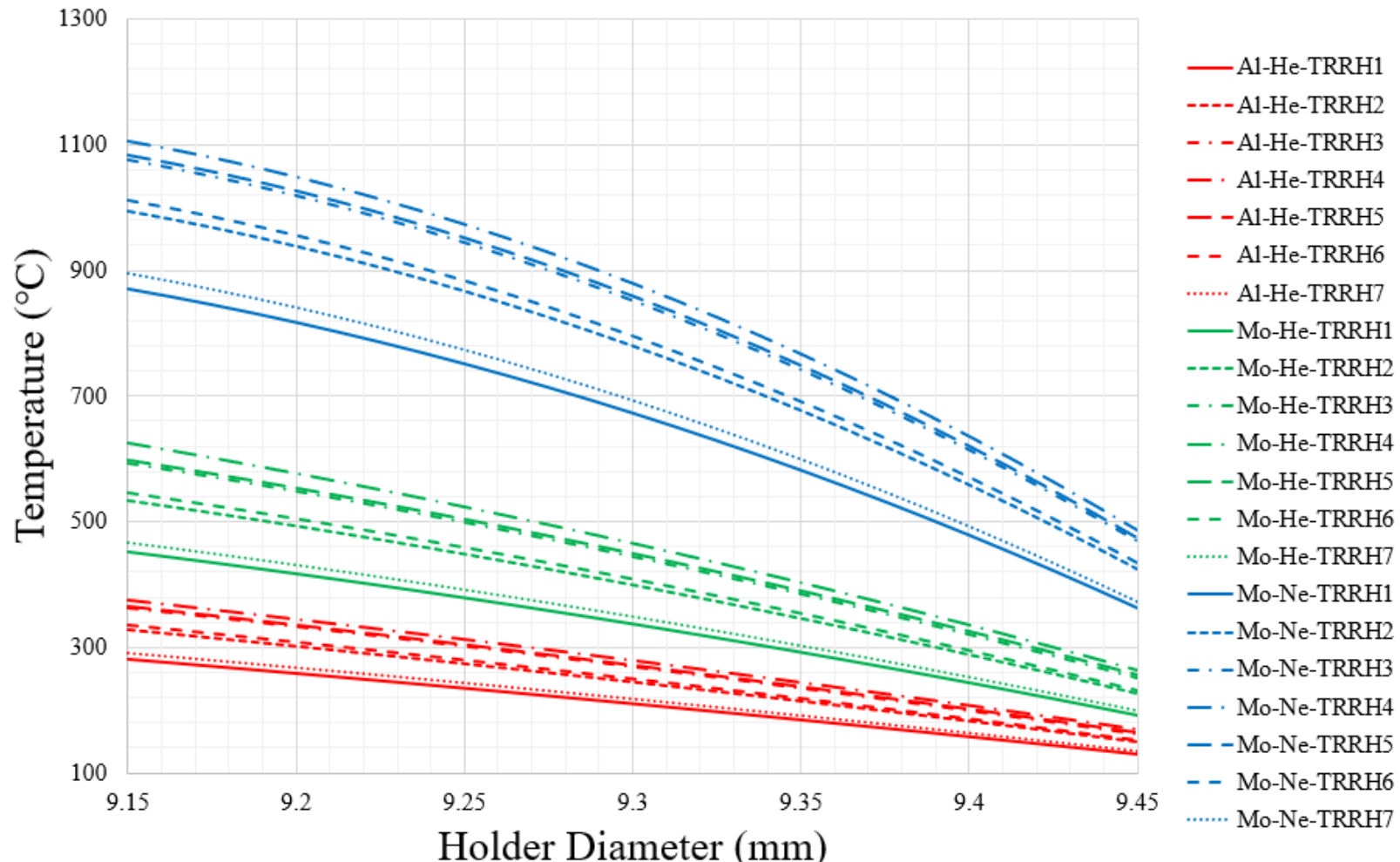

Figure 11. Representative GENTEN surface response reporting average specimen temperature as a function of holder diameter and fill gas. 


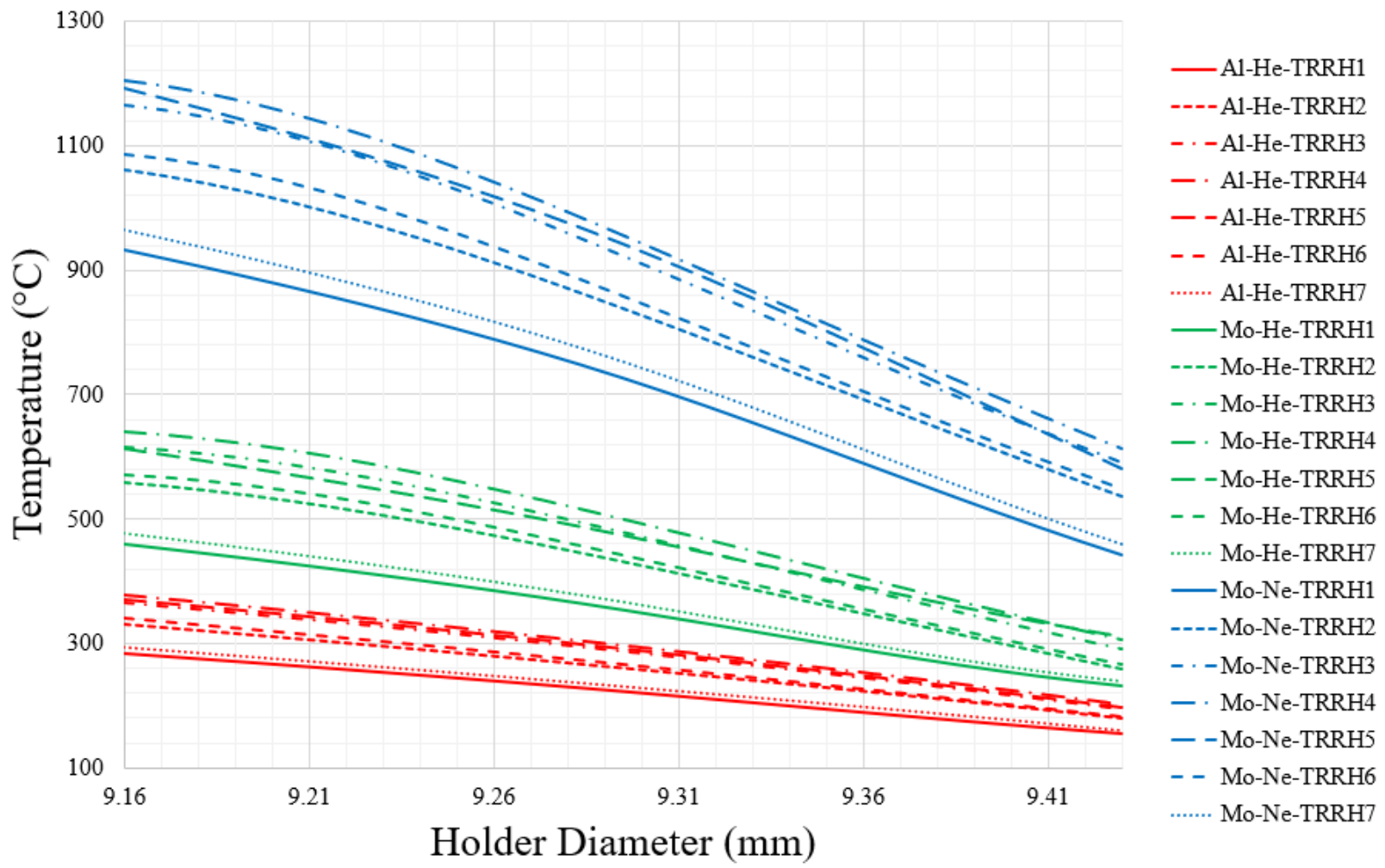

Figure 12. Representative GENBEN surface response reporting average specimen temperature as a function of holder diameter and fill gas.

\subsection{D PRINTED SS316L TEST MATRIX}

Table 6 summarizes the irradiation condition of six rabbit capsules, each of which contains 32 tensile specimens. Additively manufactured $316 \mathrm{~L}$ will be studied with slight variations in fabrication orientation. Table 7 shows the number of specimens planned for irradiation in each rabbit by orientation.

Table 6. Irradiation test matrix

\begin{tabular}{|c|c|c|c|}
\hline Capsule ID & $\begin{array}{l}\text { Irradiation } \\
\text { temperature }\end{array}$ & $\begin{array}{l}\text { Dose } \\
\text { (dpa) }\end{array}$ & Material \\
\hline GTCR01 & \multirow{3}{*}{$300^{\circ} \mathrm{C}$} & 0.2 & \multirow{6}{*}{ 3D-printed $316 \mathrm{~L}$} \\
\hline GTCR02 & & 2 & \\
\hline GTCR03 & & 8 & \\
\hline GTCR04 & \multirow{3}{*}{$600^{\circ} \mathrm{C}$} & 0.2 & \\
\hline GTCR05 & & 2 & \\
\hline GTCR06 & & 8 & \\
\hline
\end{tabular}


Table 7. Materials loading plan in different capsules

\begin{tabular}{|c|c|c|c|c|c|c|c|c|}
\hline \multirow{2}{*}{ Material type } & \multirow{2}{*}{ Base alloy } & \multirow{2}{*}{ ID* } & \multicolumn{6}{|c|}{ Number of specimens per capsule } \\
\hline & & & $\# 1$ & $\# 2$ & $\# \mathbf{3}$ & $\# 4$ & $\# 5$ & $\# 6$ \\
\hline \multirow{4}{*}{$\mathrm{AM}$} & \multirow{4}{*}{$316 \mathrm{~L}$} & TXXX & 8 & 8 & 8 & 8 & 8 & 8 \\
\hline & & TZXX & 8 & 8 & 8 & 8 & 8 & 8 \\
\hline & & $3 X X X$ & 8 & 8 & 8 & 8 & 8 & 8 \\
\hline & & $3 Z X X$ & 8 & 8 & 8 & 8 & 8 & 8 \\
\hline
\end{tabular}

*XX: ID number $(01,02,03, \ldots)$

\section{SUMMARY AND CONCLUSIONS}

Rigorous design and analysis activities for irradiation of the three main categories of TCR core materials - namely yttrium hydride and additively manufacture SiC and SS316L — are summarized in this report. The results of these planned irradiations provide confidence that the use of HFIR rabbits will be a viable path to obtaining important data on the material properties in support of the TCR program. Specifically, initial design and safety analyses show temperatures in the desired ranges for several placement options and conditions. Work is underway to order parts, assemble the rabbits, and finalize safety calculations for insertion into HFIR. This work includes reviews of both the neutronics and thermal calculations, as well as the calculations to ensure that any hydrogen released from the yttrium hydride specimens will be sufficiently contained by the sealed holder. The rapid execution of these irradiation experiments under this program will be critical to supply the necessary information to support TCR demonstration and relevant data for many other advanced reactor concepts, including various industry-led micro-reactor designs. 


\section{WORKS CITED}

[1] S. J. Zinkle, K. A. Terrani and L. L. Snead, "Motivation for utilizing new high-performance advanced materials in nuclear energy systems," Current Opinion in Solid State and Materials Science, vol. 20, pp. 401-410, 2016.

[2] Oak Ridge National Laboratory, "High Flux Isotope Reactor Technical Parameters," [Online]. Available: http://neutrons.ornl.gov/hfir/parameters. [Accessed 9 September 2019].

[3] A. Campbell, W. Porter, Y. Katoh and L. SNead, "Method for analyzing passive silicon carbide thermometry with a continuous dilatometer to determine irradiation temperature," Nuclear Instruments and Methods in Physics Research, vol. 370, pp. 49-58, 2016.

[4] Oak Ridge National Laboratory, "In-Vessel Irradiation Experiment Facilities at HFIR," [Online]. Available: https://neutrons.ornl.gov/hfir/in-vessel-irradiation\#tr. [Accessed 9 September 2019].

[5] N. Davies, and R. Forrester, "Effects of irradiation on hydrided zirconium-uranium alloy NAA 120-4 experiment," Atomics International Div., Canoga Park, CA, 1970.

[6] M. Simnad, "The U-ZrHx alloy: Its properties and use in TRIGA fuel," Nuclear Engineering and Design, vol. 64, no. 3, pp. 403-422, 1981.

[7] R. Hasslett, "Space Nuclear Thermal Propulsion Program," Gruman Aerospace Corp., Bethpage, NY, 1995.

[8] G. M. Begun, J. F. Land, and J. T. Bell, "High temperature equilibrium measurements of the yttrium-hydrogen isotope (H2, D2, T2) systems," Journal of Chemical Physics, vol. 72, no. 5, pp. 2959-2966, 1980.

[9] Los Alamos National Laboratory, "Nuclear Data Libraries from Los Alamos National Laboratory," [Online]. Available: https://nucleardata.lanl.gov/index.html. [Accessed 1 June 2019].

[10] J. L. McDuffee, "Solve Macros for ANSYS Finite Element Models With Contact Elements," DAC-11-13-ANSYS02, Rev. 6, Oak Ridge National Laboratory, Oak Ridge, TN, 2016.

[11] S. M. S. Wahid, and C. V. Madhusudana, "Gap conductance in contact heat transfer," International Journal fo Heat and Mass Transfer, vol. 43, pp. 4483-4487, 2000.

[12] J. L. McDuffee, "Heat transfer through small moveable gas gaps in a multi-body system using the ANSYS finite element software," in ASME Summer Heat Transfer Conference, Minneapolis, MN, 2013.

[13] CINDAS, LLC, "Global Benchmark for Critically Evaluated Materials Properties Data," [Online]. Available: http://cindasdata.com. [Accessed 27 July 2016].

[14] "MatWeb: Material Property Data," [Online]. Available: http://matweb.com/. [Accessed 9 September 2019].

[15] J. L. McDuffee, "Thermophysical Properties for Molybdenum," DAC-10-11-PROP_MOLY, Rev. 1, Oak Ridge National Laboratory, Oak Ridge, TN, 2013.

[16] J. L. McDuffee, "Thermophysical Properties for A16061," DAC-10-03-PROP_AL6061, Rev. 2, Oak Ridge National Laboratory, Oak Ridge, TN, 2013.

[17] P. A. Champlin, "Thermophysical Properties for Yttrium Metal and Yttrium Hydride," DAC19-03-PROP_YHX, Rev. 0, Oak Ridge National Laboratory, Oak Ridge, TN, 2019 (Forthcoming).

[18] J. L. McDuffee, "Thermophysical Properties for Irradiated SiC," DAC-10-06PROP_SIC(IRR), Rev. 3, Oak Ridge National Laboratory, Oak Ridge, TN, 2013. 
[19] D. Khatamian, and F. D. Manchester, "The H-Y (Hydrogen-Yttrium) System," Bulletin of Alloy Phase Diagrams, vol. 9, no. 3, pp. 252-260, 1988.

[20] M. Ito, et al., "Thermal properties of yttrium hydride," Journal of Nuclear Materials, vol. 344, pp. 295-297, 2005.

[21] D. Setoyama, et al., "Mechanical properties of yttrium hydride," Journal of Alloys and Compounds, vol. 394, pp. 207-210, 2005.

[22] CRC Handbook of Chemistry and Physics, Internet Version, Boca Raton, FL: CRC Press, 85th Edition, 2005.

[23] J. L. McDuffee, "Heat Transfer Coefficients and Bulk Temperatures for HFIR Rabbit Facilities," DAC-11-01-RAB03, Rev. 0, Oak Ridge National Laboratory, Oak Ridge, TN, 2011.

[24] N. O. Cetiner, "Temperature Verification and Axial Expansion Calculations for SiC BSR Rabbits," C-HFIR-2008-020, Rev. 1, Oak Ridge National Laboratory, Oak Ridge, TN, 2011.

[25] J. L. McDuffee, "Safety Analysis for Non-finned Rabbits in the Hydraulic Tube Facility Under Restricted Flow (0.5 gpm) Conditions," C-HFIR-2009-023, Rev. 0, Oak Ridge National Laboratory, Oak RIdge, TN, 2009.

[26] K.G. Field, et al., "Evaluation of the continuous dilatometer method of silicon carbide thermometry for passive irradiation temperature determination," Nuclear Instruments and Methods in Physics Research Section B: Beam Interactions with Materials and Atoms, vol. 445, pp. 46-56, 2019.

[27] C. M. Petrie, K. R. Smith, and T. J. Gerczak, "Design and Thermal Analysis for Irradiation of Pyrolytic Carbon/Silicon Carbide Diffusion Couples in the High Flux Isotope Reactor," ORNL/TM-2017/390, Oak Ridge National Laboratory, Oak Ridge, TN, 2017.

[28] C. M. Petrie, at al, "Irradiation of Miniature Fuel Specimens in the High Flux Isotope Reactor," ORNL/SPR-2018/874, Oak Ridge National Laboratory, Oak Ridge, TN, 2018.

[29] C. M. Petrie, at al., "Analysis and Experimental Qualification of an Irradiation Capsule Design for Testing Pressurized Water Reactor Fuel Cladding in the High Flux Isotope Reactor," ORNL/TM-2017/67, Oak Ridge National Laboratory, Oak Ridge, TN, 2017.

[30] C. M. Petrie, at al., "Miniature Fuel Irradiations in the High Flux Isotope Reactor," in 40th Enlarged Halden Programme Group Meeting, Lillehammer, Norway, 2017.

[31] C. M. Petrie, et al., "Design and Thermal Analysis for Irradiation of Silicon Carbide Joint Specimens in the High Flux Isotope Reactor," ORNL/TM-2018/940, Oak Ridge National Laboratory, Oak Ridge, TN, 2018.

[32] C. M. Petrie, et al., "Experimental design and analysis for irradiation of $\mathrm{SiC} / \mathrm{SiC}$ composite tubes under a prototypic high heat flux," Journal of Nuclear Materials, vol. 491, pp. 94-104, 2017.

[33] C. M. Petrie, et al., "Small-Scale Fuel Irradiation Testing in the High Flux Isotope Reactor," in Water Reactor Fuel Performance Meeting 2017, Jeju Island, Korea, 2017.

[34] P. L. Mulligan, "An F82H steel pressurized tube creep capsule for irradiation in HFIR," Nuclear Materials and Energy, vol. 15, pp. 254-260, 2018.

[35] D. Schappel and K. A. Terrani, "Key Material Properties for Thermo-Structural Analysis of TCR Core Components," Oak Ridge National Laboratory, ORNL/SPR-2019/1277, M3CT19OR06090119, Oak Ridge, 2019. 